\title{
Hydrologic Characterization of the Koshi Basin and the Impact of Climate Change
}

Luna Bharati, Pabitra Gurung and Priyantha Jayakody

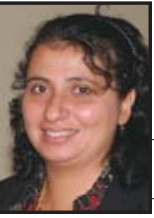

Luna Bharati

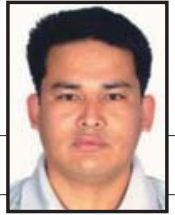

Pabitra Gurung

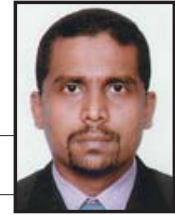

Priyantha Jayakody

Abstract: Assessment of surface and groundwater resources and water availability for different sectors is a great challenge in Nepal mainly due to data limitations. In this study, the Soil Water Assessment Tool (SWAT) was used to simulate the hydrology and to calculate sub-basin wise water balances in the Koshi Basin, Nepal. The impacts of Climate Change (CC) projections from four GCMs (CNRM-CM3, CSIRO-Mk3.0,ECHam5 and MIROC 3.2) on the hydrology of the basin were also calculated. This paper summarizes some of the key results. The full report of the study is in preparation.

The basin can be divided into the trans-mountain, central mountain, eastern mountain, eastern hill and central hill regions. Results show that current precipitation is highest in the central mountain and eastern mountain regions during both the dry and wet seasons. Water balance results showed that Actual ET as well as Runoff is also highest in the central and eastern mountain regions followed by the mid-hills. Results from climate change projections showed that average temperature will increase in the 2030's by $0.7-0.9^{\circ}$ Celsius. Results for 2030 s projections also show that during the dry season, precipitation increases in the trans-mountain but decreases in the other regions for both $\mathrm{A} 2$ and B1 scenarios. During the wet season, the MarkSim projections show a decrease in precipitation in all the regions. Net water yields also increased for the trans-mountain zone during the dry season but show varying results during the monsoon. Assessment of projected future flow time series showed that there will be an increase in the number of extreme events; i.e., both low flows and large floods. There is however; a high degree of uncertainty in the projected climate data as the relative standard deviation was quite high.

Key words: Koshi Basin, SWAT modeling, climate change, Nepal

\section{Introduction}

The Fourth Assessment of the Intergovernmental 1 Panel on Climate Change (IPCC 2007) states that due to increasing concentration of greenhouse gases in the atmosphere, for the next two decades, a warming of about $0.2^{\circ} \mathrm{C}$ per decade is projected for a range of Special Report on Emissions Scenarios (SRES).This will affect the hydrological cycle, which in turn will affect water availability, runoff and the discharge regime of rivers. The Koshi basin is one of the major snow fed river basins of Nepal. In this study, detailed spatial analysis of the hydrology of the Koshi basin under past (1976-2005) as well as future climate projections was conducted. The main objective of the study was first to model the hydrological characteristics of the Koshi basin and sub-basins and then to assess the impact of future climate projections on basin hydrology and water availability. The Soil Water Assessment Tool (SWAT) was used for this purpose. This paper summarizes some key results from the study. A full report which includes a literature review section as well as detailed assessment of the results is in preparation.

\section{Study Area: Koshi Basin}

The area considered in this study is the Kosi Basin upstream of Chatara in the mountainous region of eastern Nepal and southern Tibet (Figure 1). The study catchment area is $57,760 \mathrm{sq} . \mathrm{km}$. The study area includes the entire mountainous region in the Kosi Basin and is characterized by high climatic and geographical variability. The average elevation of the basin is $3,800 \mathrm{~m}$ but varies from $140 \mathrm{~m}$ at Chatara to more than 8,00om in the Great Himalayan Range including Mt. Everest $(8848 \mathrm{~m})$. The basin can be divided into the trans-mountain region, Central and Eastern mountain regions and the Central and Eastern hill regions. The trans-mountain, mountain and hill regions are the standard physiographic divisions of the country whereas the Central and Eastern regions are from administrative boundaries (i.e., development regions).

\section{Description of the Soil and Water Assessment tool (SWAT)}

SWAT is a process-based continuous hydrological model that predicts the impact of land management practices on water, sediment and agricultural chemical yields in complex basins with varying soils, land use and management conditions (Arnold et al 1998, Srinivasan et al 1998). The main components of the model include: climate, hydrology, erosion, soil temperature, plant growth, nutrients, pesticides, land management, channel and reservoir routing.

Conceptually SWAT divides a basin into sub-basins. Each sub-basin is connected through a stream channel and further divided into Hydrologic Response Unit (HRU). HRU is a unique combination of a soil and a vegetation type in a sub watershed, and SWAT simulates hydrology, vegetation growth, and management practices at the HRU level. Since the model maintains a continuous water balance, the subdivision of the basin enables the model to reflect differences in evapo-transpiration for various crops and soils. Thus runoff is predicted separately for each sub-basin and routed to obtain the total runoff for the basin. This increases the accuracy and gives a much better physical description of the water balance. More detailed descriptions of the model can be found in Arnold et al (1998) and Srinivasan et al (1998).

\section{Downscaled Climate Data}

In this study, the MarkSim weather generator (Jones et al2002) was used to downscale climate data from global circulation models (GCMs) gismap.ciat.cgiar.org/ 


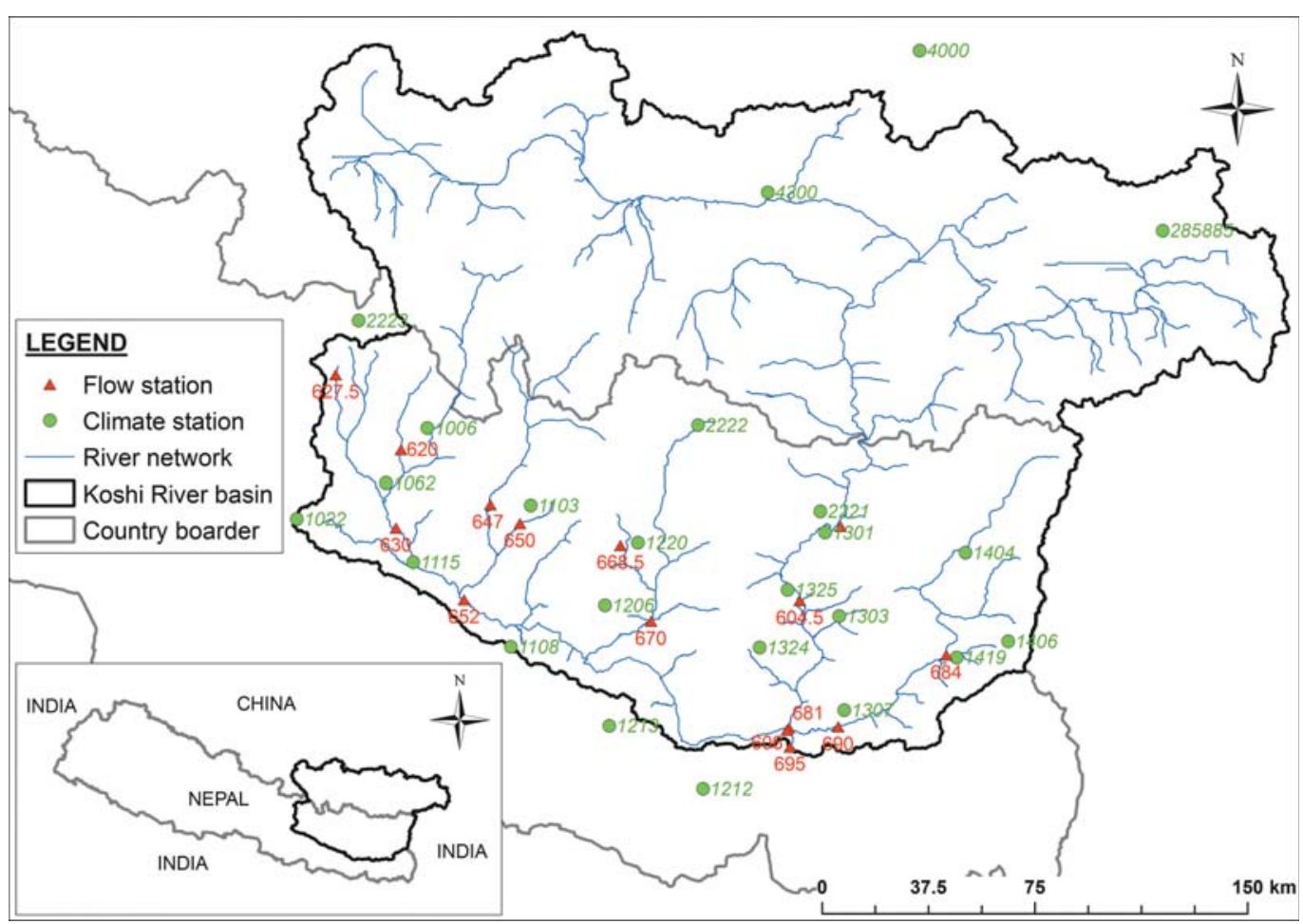

Figure 1. Map of Koshi BasinShowing the Location of Climate and Hydrological Stations Used in the Study.

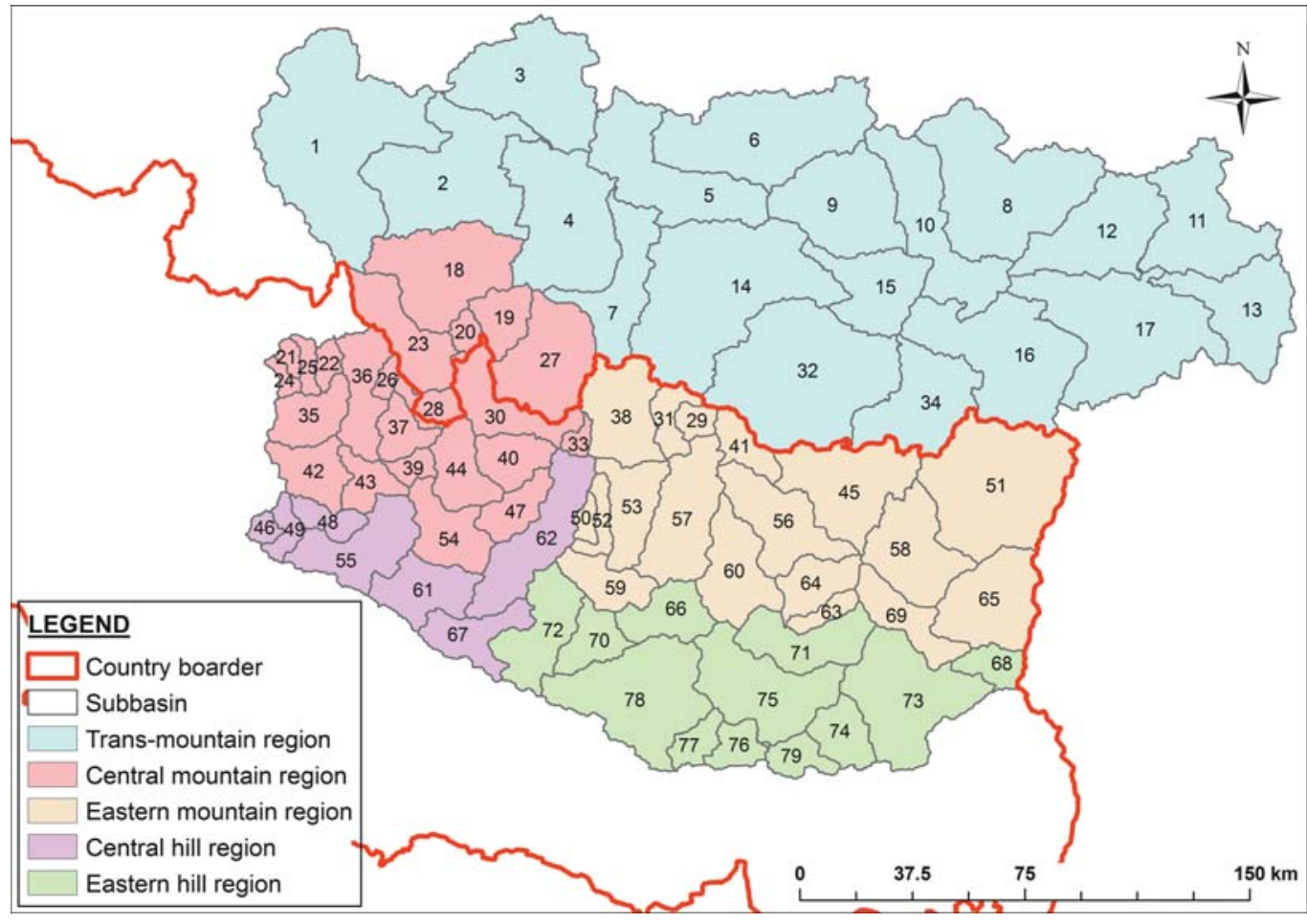

Figure 2.Division of Agro-Ecological Regions for the Koshi Basin.

MarkSimGCM. GCMs used to generate daily climate data are CNRM-CM3, CSIRO-Mk3.5, ECHam5, and MIROC3.2 and the projected data are average of these four GCMs. Baseline projections are from 1971- 2000. Future scenarios considered for this study are A2 and B1 and the period of future simulations are 2030s (average from 2016 to 2045). The A2 scenarios represent regionally oriented economic development with increases in temperature ranging from $2.0-5.4{ }^{\circ} \mathrm{C}$. The B1scenarios represent global environmental sustainability. The B1 scenarios are of a world more integrated, and more ecologically friendly and the temperature increases are $1.1-2.9$ ${ }^{\circ} \mathrm{C}$ (IPCC2007).

\section{Model Setup}

SWAT requires three basic files for delineating the basin into sub-basins and HRUs; i.e., Digital Elevation Model (DEM), Soil map and Land Use/Land Cover (LULC) map. For this study 9om Shuttle Radar Topography Mission (SRTM) was used for the DEM. Figure 3 shows the land use map (USGS, 1993) with sub-basin delineation. As can be seen from Figure 3 , forests and pasture lands dominate the upper reaches while low land areas are used for agriculture. The source of the soil map was from FAO (1995). Major soil types in the basin are Lithosols in upper areas and Dystriccambisols in lower elevation areas, dominated by agriculture.

The modeling period was from 1996 till 2005. The calibration period was from January, 1996 to December, 2000 and the validation period was from January 2001 to December, 2005 (Figure 4). Climate Data from 17 stations were used (Figure 1). Most of the available data is from the lower part of the basin in Nepal. However, data from 3 stations in Tibet were quite useful in representing the transHimalayan part of the basin.

Model simulations show very good correlation between simulated and observed flows. The correlation coefficient $\left(\mathrm{r}^{2}\right)$ for the monthly simulations is 0.96 during calibration and 0.91 during validation period. The correlation coefficient $\left(\mathrm{r}^{2}\right)$ for daily simulations is 0.86 and 0.81 for the calibration and validation period respectively. The daily 


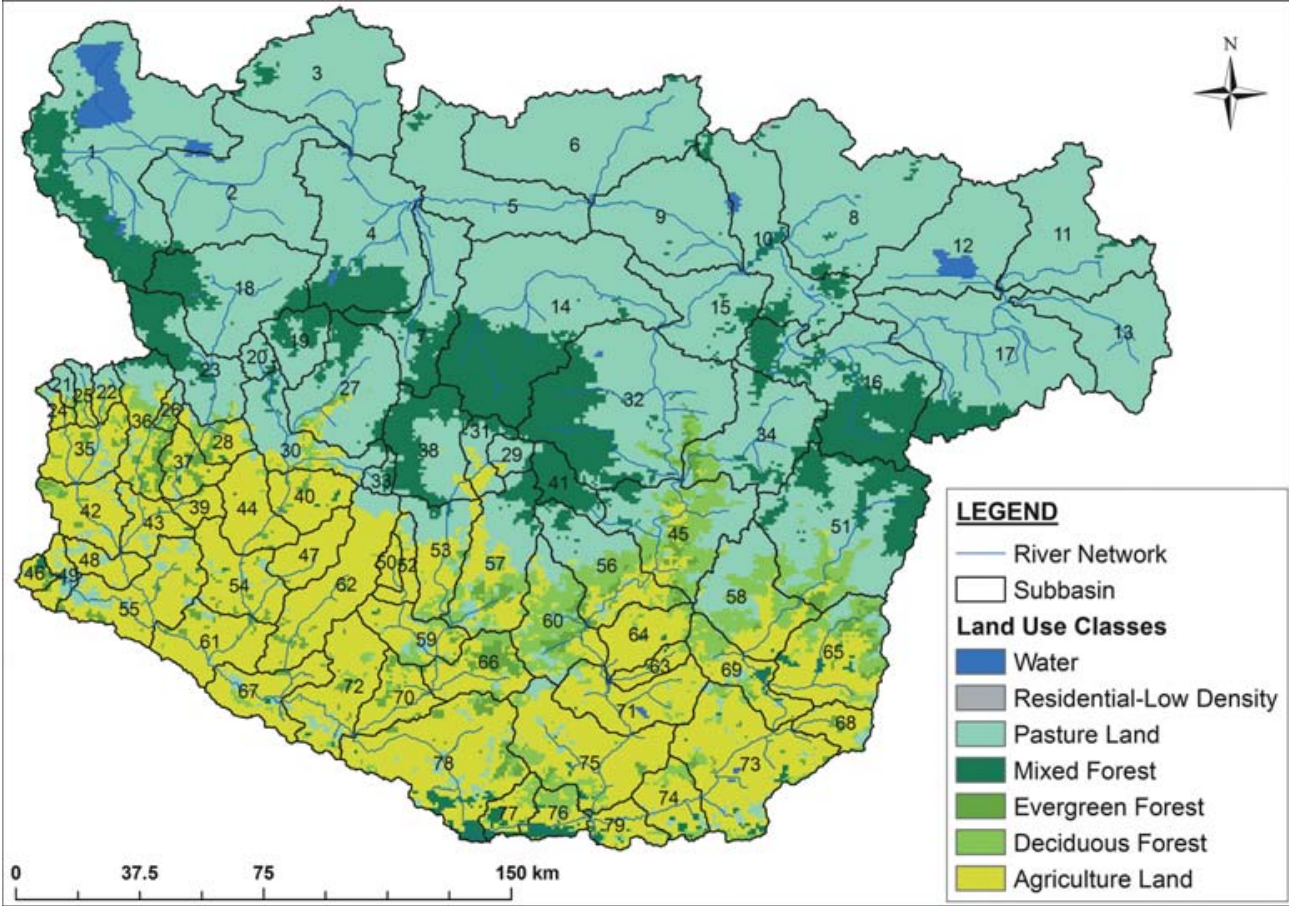

Figure 3. Land Use Map of Koshi Basin andSub-Basins Used in Hydrological Simulations (90-93 AVHRR).

\section{Results from the Water Balance Calculations}

Figure 5 presents subbasin wise distribution of precipitation, actual evapotranspiration and water yield generated using the SWAT model. As can be seen from Figure 4, the southern part of the basin is wetter than the transHimalayan northern part of the basin. Average annual precipitation is highest in the Central Mountain (1775 $\mathrm{mm}$ ) and Eastern Mountain Regions (1418 mm). Evapotranspiration (ET) is higher than runoff in the upper sub-basins. During both the dry and wet seasons, average Actual ET is highest in the Central and Eastern mountain region and lowest in the Trans-mountain simulation results show that thepeaks are underestimated during model calibration but improve during model validation. region. ET is mainly related to precipitation as well as land cover. Runoff is higher than ET in the lower sub-basins. Water yield is highest also in the mountain region and lowest in the trans-mountains. The range is, however,
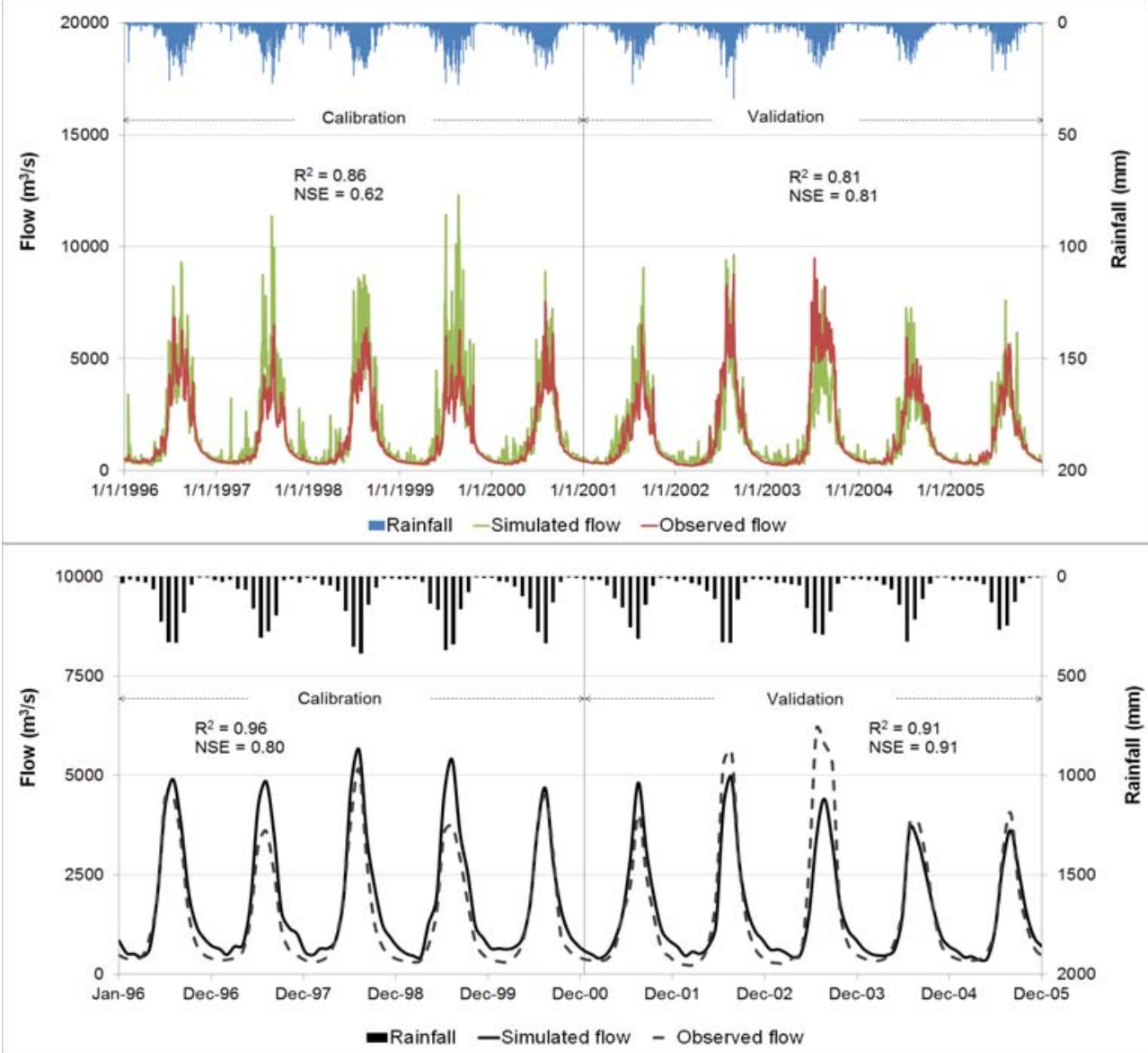

quite big with lowest of $5 \mathrm{~mm}$ during the dry season in Trans-mountain region to $1629 \mathrm{~mm}$ in the Central mountain zone.

\section{Results from CC Analysis for the Koshi Basin}

Analysis of future projections for the A2 and B1 scenarios show that the changes in average maximum temperature between baseline and projected (2030's)is $0.86^{\circ}$ Celsius and $0.79^{\circ}$ Celsius respectively. Table 1 presents mean percentage change and the relative standard deviation for precipitation under different CC scenarios and the baseline. Results for 2030's projections show that during the dry season, precipitation increases in the trans-mountain but decreases in the other regions; i.e., Central and Eastern mountains and Central and Eastern hills for Figure 4.Observed and Simulated Daily (Top) and Monthly Flows (Bottom) at the Chatara-Kothu, Sapta Koshi (Station both A2 and B1 scenarios. 695 in Figure 1) with $R^{2}$ and NSE Values. 

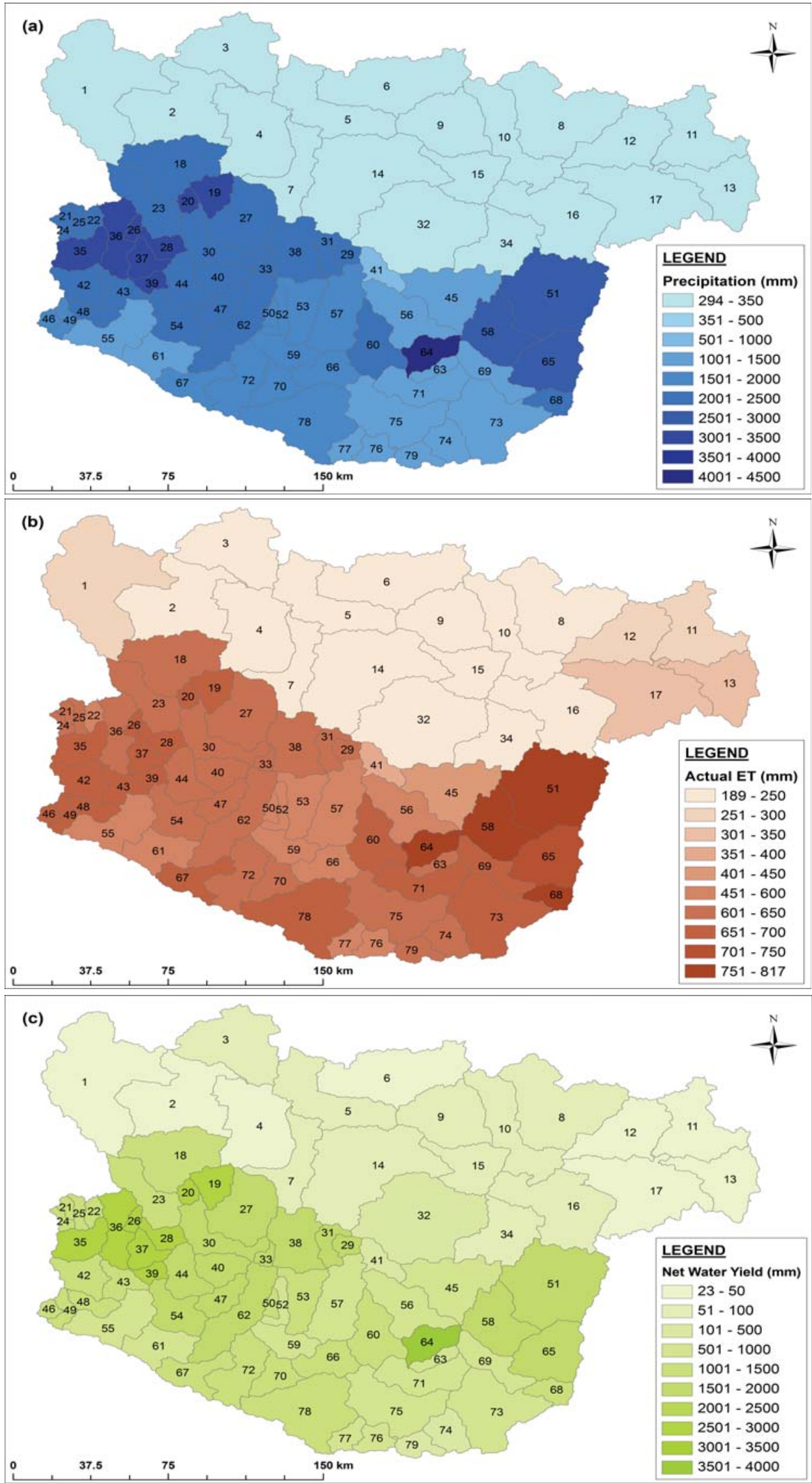

Figure 5.Sub-Basin Wise Distribution of Precipitation (a), Actual Evapo-transpiration (b) and Water Yield (c).
MarkSim projections (Both A2 and B1) show a decrease in precipitation in all the regions (Table 1). The high values for standard deviation for some of scenarios (Table 1) indicate that the data points are spread out over a large range of values and therefore, there is high uncertainty regarding the projected results. Net water yields also increase for the Trans-mountain zone during the dry season but show varying results during the monsoon. Under A2 scenarios, water yield increases for the trans-mountain and central hill region but decreases for the other regions and under B1 scenarios, there is increase in all the regions except the Eastern mountain region during the dry season.

Figure 5 presents flow time series under past (1971-2000) and $\mathrm{CC}$ projections for A2 and B1 scenarios (2016-2045) from the Koshi basin outlet. The graph (Figure 5) also highlights extreme events; i.e., extreme $(10 \%$ of daily flows for the period) and low flow events, high flow pulses (flows that exceed $75 \%$ of daily flows for the period), small floods (2yrs return interval) and large (10 years return interval) floods. Results show that the frequency of both extreme low flows as well as large flood events will increase under both the A2 and $\mathrm{B} 1$ projections. Changes in hydrological parameters such as the frequency and duration of extreme high and low flow events were also assessed. High and low pulse thresholds are the median plus or minus $25 \%$. Results show that there will be an increase in the frequency as well as duration of low flow events under both A2 and B1 scenarios. On the other hand, although the frequency of large floods increases, the frequency of high pulse events decreased for both the A2 and B1 scenarios. 

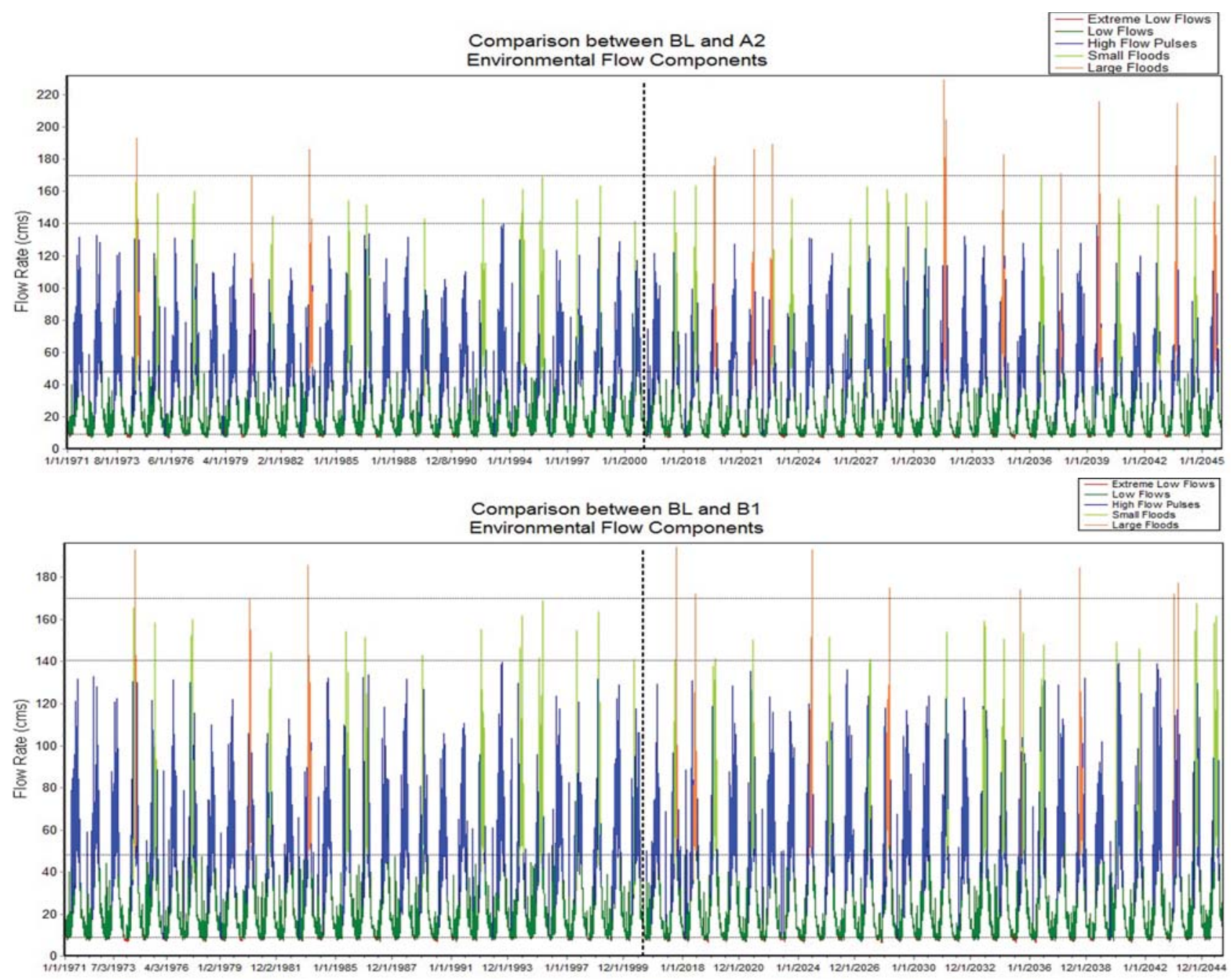

Figure 6. Flow Time Series under Baseline (1971-2000) and CC Projections for A2 and B1 Scenarios. (MarkSim 2016-2045)

\begin{tabular}{|c|c|c|c|c|c|}
\hline \multirow{2}{*}{$\begin{array}{c}\text { Ecological } \\
\text { Region }\end{array}$} & \multirow{2}{*}{$\begin{array}{c}\text { No. of } \\
\text { Sub- } \\
\text { basin }\end{array}$} & \multicolumn{2}{|c|}{ Precipitation } & \multicolumn{2}{|c|}{ Net water yield } \\
\hline & & A2 & B1 & A2 & B1 \\
\hline \multicolumn{6}{|c|}{ Dry season (Nov - May) } \\
\hline \begin{tabular}{|l|} 
Trans- \\
mountain
\end{tabular} & 19 & $29 \%(71 \%)$ & $3 \%(85 \%)$ & $138 \%(51 \%)$ & $\begin{array}{r}294 \% \\
(293 \%)\end{array}$ \\
\hline $\begin{array}{l}\text { Central } \\
\text { mountain }\end{array}$ & 23 & $-27 \%(22 \%)$ & $-25 \%(33 \%)$ & $-14 \%(19 \%)$ & $0 \%(21 \%)$ \\
\hline $\begin{array}{l}\text { Eastern } \\
\text { mountain }\end{array}$ & 18 & $-21 \%(43 \%)$ & $-22 \%(49 \%)$ & $-14 \%(16 \%)$ & $-4 \%(20 \%)$ \\
\hline Central hill & 7 & $-27 \%(14 \%)$ & $-27 \%(19 \%)$ & $-3 \%(16 \%)$ & $19 \%(16 \%)$ \\
\hline Eastern hill & 12 & $-40 \%(12 \%)$ & $-46 \%(8 \%)$ & $7 \%(28 \%)$ & $9 \%(21 \%)$ \\
\hline \multicolumn{6}{|c|}{ Wet Season (Jun - Oct) } \\
\hline $\begin{array}{l}\text { Trans- } \\
\text { mountain }\end{array}$ & 19 & $-1 \%(8 \%)$ & $-2 \%(5 \%)$ & $13 \%(5 \%)$ & $7 \%(16 \%)$ \\
\hline $\begin{array}{l}\text { Central } \\
\text { mountain }\end{array}$ & 23 & $-61 \%(15 \%)$ & $-61 \%(14 \%)$ & $-2 \%(6 \%)$ & $11 \%(7 \%)$ \\
\hline $\begin{array}{l}\text { Eastern } \\
\text { mountain }\end{array}$ & 18 & $-42 \%(32 \%)$ & $-40 \%(33 \%)$ & $-3 \%(20 \%)$ & $2 \%(19 \%)$ \\
\hline Central hill & 7 & $-24 \%(19 \%)$ & $-20 \%(27 \%)$ & $4 \%(12 \%)$ & $11 \%(9 \%)$ \\
\hline Eastern hill & 12 & $-28 \%(10 \%)$ & $-24 \%(15 \%)$ & $-2 \%(11 \%)$ & $7 \%(17 \%)$ \\
\hline
\end{tabular}

Table 1. Mean Percentage Change and Percent Standard Deviation ( in Brackets) in Dry and Wet Seasons under 2030s Projection

\section{Conclusion}

Assessment of the Koshi basin water balance showed that there is large temporal and spatial variability in precipitation, actual evapo-transpiration and water yield in the basin. In the upper part of basin, runoff is greater that evapo-transpiration whereas in the lower parts of the basin evapo-transpiration is greater that runoff. Understanding of and adapting to existing climate variability is critical for adaptation to future climates as there is still high level of uncertainty in future climate change projections. Results from this study show an increase in temperature and reduction in mean annual rainfall for most of the Koshi basin however, instead of looking at annual averages and trends, when environmental components such as frequency of high and low flows were assessed, results showed that there will be an increase in the number of extreme events; i.e., both low flows and large floods.

There is however; a large degree of uncertainty related to climate projections. Therefore, instead of planning for certain trends, adaptation strategies would do better to focus on reducing risks of both high and low flows. Investments in systems which reduce risk such as storage development, climate insurance schemes, inter-institutional cooperation are some possible adaptation options.

Continued on Page 120... 